\title{
The Association between Pretreatment anemia and Overall Survival in Advanced Non-small Cell lung Cancer: A Retrospective Cohort Study Using Propensity Score Matching
}

\author{
Yucong Huang ${ }^{1 *}$, Cuiyun $\mathrm{Su}^{1^{*}}$, Huiqin Jiang${ }^{2}$, Feiwen $\mathrm{Liu}^{2}$, Qitao $\mathrm{Yu}^{1}$, Shaozhang Zhou ${ }^{1 凶}$ \\ 1. Department of Respiratory Oncology, Guangxi Medical University Affiliated Tumor Hospital, No.71 Heti Road, 530021, Nanning City, Guangxi Zhuang \\ Autonomous Region, China. \\ 2. Oncology Medical College, Guangxi Medical University, No.22 Shuangyong Road, 530021, Nanning City, Guangxi Zhuang Autonomous Region, China. \\ * Yucong Huang and Cuiyun Su contributed equally to this work. \\ $\square$ Corresponding author: Shaozhang Zhou, Department of Respiratory Oncology, Guangxi Medical University Affiliated Tumor Hospital, No.71 Heti Road, \\ 530021, Nanning City, Guangxi Zhuang Autonomous Region, China. Phone: +86-0771-5334955; Fax: +86-0771-5300613; Email: zhoushaozhang@gxmu.edu.cn \\ (c) The author(s). This is an open access article distributed under the terms of the Creative Commons Attribution License (https://creativecommons.org/licenses/by/4.0/). \\ See http://ivyspring.com/terms for full terms and conditions.
}

Received: 2020.10.28; Accepted: 2021.10.08; Published: 2022.01.01

\begin{abstract}
Background: The purpose of this study was to investigate whether pretreatment anemia was an independent risk factor for survival in patients with advanced non-small cell lung cancer (NSCLC) after adjusting for other covariates.

Methods: We used propensity score matching (PSM) to minimize the influence of confounding factors and used X2 (categorical variables), Student's t-test (normal distribution), or Mann-Whitney $U$ test (skewed distribution) to analyze the differences among the $\mathrm{Hb}$ groups. Cox regression and Kaplan-Meier analyses were used to assess the association between anemia and survival. $\mathrm{P}$ values $<0.05$ (two-sided) were considered statistically significant.

Results: The average age of the 758 selected participants was $58.2 \pm 11$ years, and 210 patients $(27.7 \%)$ had anemia. In the multivariate analysis, anemia was associated with a poor prognosis in the unmatched cohort (Hazards ratio $(H R)=1.3,95 \%$ (confidence interval $(\mathrm{Cl}): 1.1-1.6 ; p=0.008)$, and the matched cohort $(H R=1.7$, $95 \% \mathrm{Cl}: 1.3-2.3 ; \mathrm{p}<0.001$ ), emerging as an independent risk and prognostic factor in advanced NSCLC patients. In the Kaplan-Meier curve, the average survival time of anemic and non-anemic patients was 9.3 months $(95 \%$ Cl: 7.9-11.4 months) vs. 14.1 months $(95 \% \mathrm{Cl}: 12-16.3$ months) $(p=0.0073)$ in the unmatched cohort. After propensity score matching, the average survival time of anemic and non-anemic patients was 10.9 months $(95 \%$ $\mathrm{Cl}$ : 8.8-12.9. months) vs. 17.8 months ( $95 \% \mathrm{Cl}: 16.0-23.3$ months) $(\mathrm{p}<0.001)$.
\end{abstract}

Conclusion: Pretreatment anemia was an independent risk and prognostic factor for survival in patients with advanced NSCLC. Large-scale studies are required to confirm our findings.

Key words: anemia, advanced NSCLC, overall survival, prognosis, propensity score matching

\section{Introduction}

In China, lung cancer contributes to the highest proportion of morbidity within the male population and is the second-highest cause of common malignant tumors in women [1]. Furthermore, the mortality rate associated with the incidence of lung cancers ranks first in tumor-related deaths worldwide [2]. Non-small cell lung cancer (NSCLC) accounts for 85\% of all lung cancers, and a majority of these patients are confirmed to have an advanced stage of the disease during initial diagnosis [3]. Despite rapid advancements in medical science, such as extensive use of targeted therapy and immunotherapy in clinical practice, the prognosis of advanced NSCLC remains poor, with a 5-year survival rate ranging 
from $5-16 \%[4]$.

Anemia is a common hematological abnormality among patients with advanced malignancies. It is reported that approximately $40-64 \%$ of the patients with malignant tumors experience anemia during the entire course of the disease [5].In a multicenter cross-sectional study conducted in China in 2012, the incidence of cancer-related anemia was $49.24 \%$ [6].

The incidence of anemia in patients with malignancies is influenced by many factors, and has not been fully clarified yet. The known causes include the tumor itself (such as blood loss, hemolysis, bone marrow invasion) and tumor treatment (such as bone marrow suppression by chemotherapy or radiotherapy, drugs that lead to impaired renal function). The deficiency of iron, folic acid, and vitamin B12 also plays an important role in the manifestation of anemia.

Several studies have shown that anemia is associated with poor overall survival (OS) in various advanced cancers, such as gastric carcinoma, prostate carcinoma, non-Hodgkin's lymphoma, and cervical cancer [7]. However, the relationship between anemia and survival outcomes in patients with advanced NSCLC remains controversial. Some evidence indicates that anemia is associated with poor prognosis [8-13], while other studies failed to identify whether anemia was related to survival in patients with NSCLC [14-18]. The divergence of the results in these studies may be contributed by differences in the study design, sample size $e_{L}$ race, clinicopathological features, etc. Most importantly, the imbalance between the two groups for comparison also has a crucial influence on the results.

Thus, we performed this retrospective study with a large-scale population to evaluate whether pretreatment anemia was associated with OS in patients with advanced NSCLC, using propensity score matching (PSM) to eliminate the differences between anemia and non-anemia groups.

\section{Patients and Methods}

\section{Patients}

Patients with advanced NSCLC, who were treated at the Guangxi Medical University Affiliated Cancer Hospital between December 2010 and October 2018 were screened for the study. This study was reviewed and approved by the Ethics Committee of the Hospital. Due to the retrospective nature of the cohort study, the necessity to obtain informed consent from each patient was waived. The inclusion criteria were as follows: (1) pathological or cytologically confirmed NSCLC; (2) manifestation of stage IIIB or IV NSCLC as per the seventh edition of the American
Joint Committee on Cancer (AJCC) staging system; (3) availability of complete blood cell count and follow-up data; and (4) treatment-naïve, previously. The exclusion criteria were as follows: (1) complicated with hematological diseases causing anemia or renal anemia; (2) had a history of anemia before diagnosis; and (3) had no concurrent malignancy or a history of a second primary malignancy. Finally, a total of 758 patients who met the outlined criteria were enrolled in this study (Figure 1).

\section{Data collection and variable definitions}

In our study, we summarized the following confounders that were reported in previous literature: (1) demographic characteristics; (2) variables that affect anemia or prognostic value reported in previous literature; and (3) evaluation based on our clinical experience. Therefore, the following variables were included: age, sex, smoking history, eastern cooperative oncology group performance status (ECOG PS), body mass index (BMI), pathology type, differentiation, status for anaplastic lymphoma kinase (ALK) fusion, and epidermal growth factor receptor (EGFR) mutation, sum of metastasis organs, treat type of first-line therapy, and the sum of treatment lines.

We obtained the baseline hemoglobin $(\mathrm{Hb})$ levels of all subjects from the electronic medical record system of the hospital. According to the National Cancer Institute criteria and the ninth edition of expert panel in the field of Hematology in China, the definition of anemia was when $\mathrm{Hb}$ levels were $<12$ $\mathrm{g} / \mathrm{dL}$ in men and $<11 \mathrm{~g} / \mathrm{dL}$ in women [19-21]. In addition, OS is defined as the time from diagnosis to the date of death from any cause or the last follow-up in July 31, 2020.

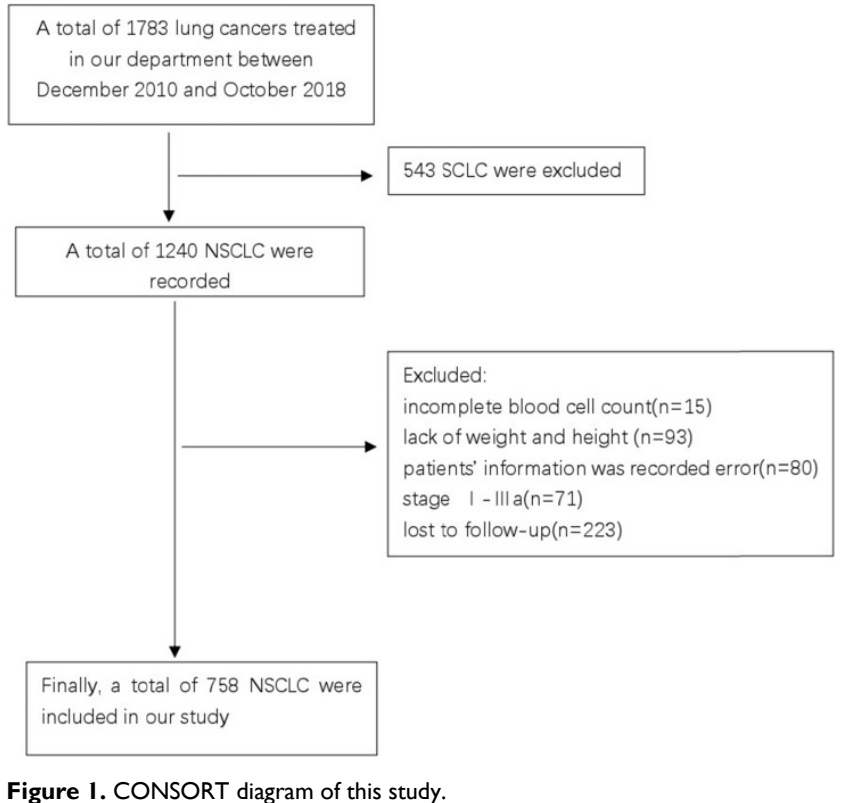


The definitions of clinicopathological characteristics or parameters used in this study were based on several available classification systems. Notably, individuals who smoked more than 100 cigarettes in their lifetime were defined as smokers. Tumors were histologically classified according to the 3 rd version of the World Health Organization (WHO) criteria for tumors. The performance status of patients was measured using the ECOG score. BMI was calculated by weight in kilograms divided by the square of the height in meters [22]. In our study, we classified BMI into underweight $(<18 \mathrm{~kg} / \mathrm{m} 2)$, normal weight $(\leq 18.5-$ $<25 \mathrm{~kg} / \mathrm{m} 2)$, and overweight $(\geq 25 \mathrm{~kg} / \mathrm{m} 2)$ categories, respectively [23]. ALK fusion was detected by fluorescence in situ hybridization (FISH), immunohistochemistry (IHC), or reverse transcriptionpolymerase chain reaction (RT-PCR) [24]. Detection of EGFR sensitive mutations (19 exon deletions or 21 exon L858R) was based on the methods of amplification refractory mutation system (ARMS), droplet digital polymerase chain reaction (ddPCR), or next-generation sequencing (NGS) [25]. The sum of metastasis organs was counted by organs with tumor metastasis, it should be noted that even if an organ had multiple lesions is only counted once. The first-line therapy included chemotherapy (single-drug chemotherapy or platinum-based dual-doublet chemotherapy), targeted therapy (including EGFR-TKIs or ALK-TKIs therapy), and others such as immunotherapy, radiation therapy, and antiangiogenic therapy.

Follow-up analyses were performed by the first two authors of this study. The cut-off date for the patients' follow-up was July 31, 2020. The follow-up interval was 3 months.

\section{Data analysis}

In this study, PSM was performed to minimize the influence of confounding factors between the comparing groups, and 1:1 matching was performed between anemic and non-anemic patients, using a caliper width of 0.1 times the standard deviation of the propensity score. There were 151 matched pairs in the PSM cohort.

In the PSM cohort and adjusted cohort, we adjusted the covariates which may interfere with the results as the mixed factors, including the age, sex, smoking history, ECOG PS, BMI, pathology, differentiation, ALK fusion, EGFR mutation, sum of metastasis organs (obtained at baseline), treat type of 1 st line therapy, and the sum of treatment lines.

We used $\chi^{2}$ (categorical variables) test, Student's $\mathrm{t}$-test (continuous variables with normal distribution), or Mann-Whitney $U$ test (continuous variables skewed distribution) to analyze the differences between anemia and non-anemia groups. Survival was estimated using the Kaplan-Meier method, and the difference in survival was evaluated with a stratified log-rank test. Multivariable analyses with the Cox proportional-hazards model were used to estimate the prognostic effect of anemia on survival. Covariates were included as potential confounders in the fully adjusted models to assess whether they could modify the influence of anemia on OS by more than $10 \%$ or were significantly associated with survival, with a $\mathrm{P}$ value less than 0.05 . All analyses were performed using the statistical software packages $\mathrm{R}$ (http://www.R-project.org, The R Foundation) and Empower Stats (http://www .empowerstats.com, X\&Y Solutions, Inc., Boston, MA). $P$ values less than 0.05 (two-sided) were considered statistically significant.

\section{Results}

\section{Clinical characteristics}

In total, 758 patients with advanced NSCLC were selected for the study. The clinical characteristics are shown in Table 1 . In brief, approximately $68.1 \%$ of them were men, and 210 were diagnosed with anemia at baseline $(27.7 \%)$. The levels of smoking history, ECOG PS, BMI, pathology, and EGFR mutation were significantly different $(p<0.05)$ in the pre-matched cohort, while after propensity matching, 151 pairs of patients were selected from the two groups wherein differences were reduced in all confounders and there was no statistical significance in either the anemic or the non-anemic patients.

\section{Univariates analysis}

The results of the univariate analyses are listed in Table 2. According to the results of the univariate Cox proportional hazard model, we identified that irrespective of the matching, covariates such as smoking, ECOG PS $\geq 2$, squamous cell carcinoma, and anemia were associated with poor prognosis in patients with advanced lung cancer. However, age $\geq$ 60 years (hazards ratio (HR): 1.3, 95\% confidence interval (CI): 1.1-1.5; $\mathrm{p}=0.07$ ), male sex (HR: 1.2, 95\% CI: 1.0-1.5; $\mathrm{p}=0.021)$, sum of metastasis organs $\geq 2$ (HR: 1.4, 95\% CI: 1.1-1.7; $\mathrm{p}=0.008$ ) were observed to be statistically significant before propensity score matching, while subsequent to PSM, they were not statistically significant (age $\geq 60$ [HR: $1.3,95 \%$ CI: 0.91.7; $\mathrm{p}=0.121$ ], male sex [HR: 1.6, 95\% CI: 1.1-2.2; $\mathrm{p}=0.07]$, and the sum of metastasis organs $\geq 2$ [HR: 1.4, 95\% CI: $1.0-2.1 ; p=0.071])$. Moreover, the sum of treatment lines $>3$ was found to be a protective factor for survival before and after matching. 
Table 1. Baseline characteristics of participants.

\begin{tabular}{|c|c|c|c|c|c|c|}
\hline \multirow[t]{2}{*}{ Variables } & \multicolumn{3}{|c|}{ Before propensity matching } & \multicolumn{3}{|c|}{ After propensity matching } \\
\hline & No anemia & Anemia & P-value & No anemia & Anemia & P-value \\
\hline Age & & & 0.097 & & & 0.645 \\
\hline$<60$ & $303(55.3 \%)$ & $102(48.6 \%)$ & & $74(49.0 \%)$ & $78(51.7 \%)$ & \\
\hline$\geq 60$ & $245(44.7 \%)$ & $108(51.4 \%)$ & & $77(51.0 \%)$ & $73(48.3 \%)$ & \\
\hline Sex & & & 0.055 & & & 0.797 \\
\hline female & $186(33.9 \%)$ & $56(26.7 \%)$ & & $43(28.5 \%)$ & $41(27.2 \%)$ & \\
\hline male & $362(66.1 \%)$ & $154(73.3 \%)$ & & $108(71.5 \%)$ & $110(72.8 \%)$ & \\
\hline Smoking history & & & 0.005 & & & 0.555 \\
\hline Never & $284(51.8 \%)$ & $85(40.5 \%)$ & & $73(48.3 \%)$ & $66(43.7 \%)$ & \\
\hline Ever & $259(47.3 \%)$ & $119(56.7 \%)$ & & $76(50.3 \%)$ & $81(53.6 \%)$ & \\
\hline unknown & $5(0.9 \%)$ & $6(2.9 \%)$ & & $2(1.3 \%)$ & $4(2.6 \%)$ & \\
\hline ECOG PS & & & $<0.001$ & & & 0.171 \\
\hline$<2$ & $457(83.4 \%)$ & $152(72.4 \%)$ & & $129(85.4 \%)$ & $119(78.8 \%)$ & \\
\hline$\geq 2$ & $52(9.5 \%)$ & $40(19.0 \%)$ & & $11(7.3 \%)$ & $21(13.9 \%)$ & \\
\hline unknown & $39(7.1 \%)$ & $18(8.6 \%)$ & & $11(7.3 \%)$ & $11(7.3 \%)$ & \\
\hline $\mathrm{BMI}^{*}$ & & & 0.005 & & & 0.925 \\
\hline$<18.5$ & $67(12.6 \%)$ & $44(22.0 \%)$ & & $28(18.5 \%)$ & $27(17.9 \%)$ & \\
\hline$\geq 18.5,<25$ & $398(74.8 \%)$ & $137(68.5 \%)$ & & $109(72.2 \%)$ & $108(71.5 \%)$ & \\
\hline$\geq 25$ & $67(12.6 \%)$ & $19(9.5 \%)$ & & $14(9.3 \%)$ & $16(10.6 \%)$ & \\
\hline Pathology & & & $<0.001$ & & & 0.098 \\
\hline adenocarcinoma & $426(77.7 \%)$ & $138(65.7 \%)$ & & $108(71.5 \%)$ & $107(70.9 \%)$ & \\
\hline squamous cell carcinoma & $101(18.4 \%)$ & $66(31.4 \%)$ & & $33(21.9 \%)$ & $41(27.2 \%)$ & \\
\hline others & $21(3.8 \%)$ & $6(2.9 \%)$ & & $10(6.6 \%)$ & $3(2.0 \%)$ & \\
\hline Differentiation & & & 0.092 & & & 0.534 \\
\hline poor & $193(35.2 \%)$ & $74(35.2 \%)$ & & $47(31.1 \%)$ & $56(37.1 \%)$ & \\
\hline moderate & $48(8.8 \%)$ & $31(14.8 \%)$ & & $15(9.9 \%)$ & $18(11.9 \%)$ & \\
\hline high & $18(3.3 \%)$ & $5(2.4 \%)$ & & $5(3.3 \%)$ & $3(2.0 \%)$ & \\
\hline unknown & $289(52.7 \%)$ & $100(47.6 \%)$ & & $84(55.6 \%)$ & $74(49.0 \%)$ & \\
\hline ALK fusion & & & 0.629 & & & 0.563 \\
\hline negative & $213(38.9 \%)$ & $74(35.2 \%)$ & & $62(41.1 \%)$ & $55(36.4 \%)$ & \\
\hline positive & $22(4.0 \%)$ & $8(3.8 \%)$ & & $9(6.0 \%)$ & $7(4.6 \%)$ & \\
\hline unknown & $313(57.1 \%)$ & $128(61.0 \%)$ & & $80(53.0 \%)$ & $89(58.9 \%)$ & \\
\hline EGFR mutation & & & 0.007 & & & 0.055 \\
\hline negative & $139(25.4 \%)$ & $56(26.7 \%)$ & & $41(27.2 \%)$ & $45(29.8 \%)$ & \\
\hline positive & $110(20.1 \%)$ & $22(10.5 \%)$ & & $35(23.2 \%)$ & $19(12.6 \%)$ & \\
\hline unknown & $299(54.6 \%)$ & $132(62.9 \%)$ & & $75(49.7 \%)$ & $87(57.6 \%)$ & \\
\hline Sum of metastasis organs & & & 0.747 & & & 0.871 \\
\hline$<2$ & $102(18.6 \%)$ & $43(20.5 \%)$ & & $27(17.9 \%)$ & $29(19.2 \%)$ & \\
\hline$\geq 2$ & $435(79.4 \%)$ & $164(78.1 \%)$ & & $121(80.1 \%)$ & $120(79.5 \%)$ & \\
\hline unknown & $11(2.0 \%)$ & $3(1.4 \%)$ & & $3(2.0 \%)$ & $2(1.3 \%)$ & \\
\hline Treat type of 1st line therapy & & & 0.556 & & & 0.891 \\
\hline Chemo & $272(49.6 \%)$ & $106(50.5 \%)$ & & $95(62.9 \%)$ & $99(65.6 \%)$ & \\
\hline TKI & $90(16.4 \%)$ & $28(13.3 \%)$ & & $28(18.5 \%)$ & $26(17.2 \%)$ & \\
\hline others & $186(33.9 \%)$ & $76(36.2 \%)$ & & $28(18.5 \%)$ & $26(17.2 \%)$ & \\
\hline Sum of treatment lines* & & & 0.257 & & & 0.123 \\
\hline$\leq 3$ & $374(87.4 \%)$ & $147(90.7 \%$ & & $127(84.1 \%)$ & $136(90.1 \%)$ & \\
\hline$>3$ & $54(12.6 \%)$ & $15(9.3 \%)$ & & $24(15.9 \%)$ & $15(9.9 \%)$ & \\
\hline
\end{tabular}

\section{Results of crude and adjusted Cox proportional hazards models}

In our study, two models were constructed to independently analyze the effects of anemia on survival (Crude model and Adjusted model). The HRs and $95 \%$ CI are listed in Table 3. Prior to PSM, when compared with the non-anemia group, the anemia group exhibited an increased risk of death by $30 \%$ (HR:1.3, 95\%CI:1.1-1.6; $p=0.008$ ). In the adjusted model before PSM, the risk of death in the anemia group was significantly higher than that in the non-anemia group (HR: 1.4, 95\%CI: 1.1-1.7; $\mathrm{p}=0.013$ ). After using PSM to minimize the covariates, the result was similar to that of the pre-match model. Anemia continued to remain a significant risk predictor for advanced NSCLC patients (HR:1.7, 95\%CI:1.3-2.3; p $<0.001$ ) in the crude model and (HR:1.6,95\% CI:1.2-2.2; $\mathrm{p}=0.003$ ) in the adjusted model. Moreover, it was also found that decrease in hemoglobin levels by $1 \mathrm{~g} / \mathrm{dL}$ led to a concomitant increase in the risk of death by $10 \%$.

\section{Subgroup analysis}

Univariate analysis showed that anemia was negatively correlated with the overall survival of the patients. Further, subgroup analyses were performed to understand this negative relationship. We used age, 
sex, smoking history, ECOG PS, BMI, pathology, differentiation, ALK fusion, EGFR mutation, sum of metastasis organs, treat type of 1st line therapy, and the sum of treatment lines as the stratification variables to observe the trend of effect sizes in these variables (Figure 2 and Figure 3). We noted that the majority of subgroups displayed a stable relationship between anemia and survival in the two models.

\section{Kaplan-Meier survival analysis}

As shown in Figure 4, the median OS of pre-matched patients in the anemia and the non-anemia group was 9.3 months (95\%CI:7.9-11.4m) and 14.1 months (95\%CI:12-16.3m), respectively $(\mathrm{P}=0.0073)$. Notably, there was also a significant difference in the median OS between the two groups after propensity score matching (Figure 5). The median OS of patients with anemia was 10.9 months $(95 \% \mathrm{CI}: 8.8-12.9 \mathrm{~m})$ compared to 17.8 months (95\%CI:16-23.3 m) in patients without anemia ( $\mathrm{P}$ $<0.001)$.

Table 2. Univariate and analysis of overall survival.

\begin{tabular}{|c|c|c|c|c|c|c|}
\hline \multirow[t]{2}{*}{ Variables } & \multicolumn{3}{|c|}{ Before propensity matching } & \multicolumn{3}{|c|}{ After propensity matching } \\
\hline & Statistics & $\mathrm{HR}(95 \% \mathrm{CI})$ & P-value & Statistics & $\mathrm{HR}(95 \% \mathrm{CI})$ & P-value \\
\hline \multicolumn{7}{|l|}{ Age } \\
\hline$<60$ & $405(53.4 \%)$ & 1 & & $152(50.3 \%)$ & 1 & \\
\hline$\geq 60$ & $353(46.6 \%)$ & $1.3(1.1,1.5)$ & 0.007 & $150(49.7 \%)$ & $1.3(0.9,1.7)$ & 0.121 \\
\hline \multicolumn{7}{|l|}{ Sex } \\
\hline female & $242(31.9 \%)$ & 1 & & $84(27.8 \%)$ & 1 & \\
\hline male & $516(68.1 \%)$ & $1.2(1.0,1.5)$ & 0.021 & $218(72.2 \%)$ & $1.6(1.1,2.2)$ & 0.07 \\
\hline \multicolumn{7}{|l|}{ Smoking history } \\
\hline Never & $369(48.7 \%)$ & 1 & & $139(46.0 \%)$ & 1 & \\
\hline Ever & $378(49.9 \%)$ & $1.4(1.2,1.7)$ & $<0.001$ & $157(52.0 \%)$ & $1.7(1.3,2.3)$ & $<0.001$ \\
\hline unknown & $11(1.5 \%)$ & $4.0(2.2,7.3)$ & $<0.001$ & $6(2.0 \%)$ & $4.4(1.9,10.2)$ & $<0.001$ \\
\hline \multicolumn{7}{|l|}{ ECOG PS } \\
\hline$<2$ & $609(80.3 \%)$ & 1 & & $248(82.1 \%)$ & 1 & \\
\hline$\geq 2$ & $92(12.1 \%)$ & $1.5(1.1,1.9)$ & 0.003 & $32(10.6 \%)$ & $1.9(1.2,2.9)$ & 0.003 \\
\hline unknown & $57(7.5 \%)$ & $1.3(1.0,1.8)$ & 0.051 & $22(7.3 \%)$ & $1.4(0.9,2.3)$ & 0.151 \\
\hline \multicolumn{7}{|l|}{ BMI* } \\
\hline$<18.5$ & $111(15.2 \%)$ & 1 & & $55(18.2 \%)$ & 1 & \\
\hline$\geq 18.5,<25$ & $535(73.1 \%)$ & $0.9(0.7,1.1)$ & 0.351 & $217(71.9 \%)$ & $0.9(0.6,1.3)$ & 0.688 \\
\hline$\geq 25$ & $86(11.7 \%)$ & $0.7(0.5,1.0)$ & 0.049 & $30(9.9 \%)$ & $0.6(0.4,1.1)$ & 0.127 \\
\hline \multicolumn{7}{|l|}{ Pathology } \\
\hline adenocarcinoma & $564(74.4 \%)$ & 1 & & $215(71.2 \%)$ & 1 & \\
\hline squamous cell carcinoma & $167(22.0 \%)$ & $1.4(1.2,1.8)$ & 0.001 & $74(24.5 \%)$ & $1.6(1.1,2.2)$ & 0.006 \\
\hline others & $\begin{array}{l}27 \\
(3.6 \%)\end{array}$ & $1.2(0.7,1.8)$ & 0.512 & $\begin{array}{l}13 \\
(4.3 \%)\end{array}$ & $1.4(0.7,2.7)$ & 0.311 \\
\hline \multicolumn{7}{|l|}{ Differentiation } \\
\hline poor & $267(35.2 \%)$ & 1 & & $103(34.1 \%)$ & 1 & \\
\hline moderate & $79(10.4 \%)$ & $0.8(0.6,1.1)$ & 0.22 & $33(10.9 \%)$ & $0.8(0.5,1.2)$ & 0.292 \\
\hline high & $23(3.0 \%)$ & $0.8(0.5,1.3)$ & 0.449 & $8(2.6 \%)$ & $1.2(0.6,2.6)$ & 0.64 \\
\hline unknown & $389(51.3 \%)$ & $0.7(0.6,0.8)$ & $<0.001$ & $158(52.3 \%)$ & $0.7(0.5,1.0)$ & 0.059 \\
\hline \multicolumn{7}{|l|}{ ALK fusion } \\
\hline negative & $287(37.9 \%)$ & 1 & & $117(38.7 \%)$ & 1 & \\
\hline positive & $30(4.0 \%)$ & $0.7(0.4,1.2)$ & 0.154 & $16(5.3 \%)$ & $0.5(0.2,1.3)$ & 0.155 \\
\hline unknown & $441(58.2 \%)$ & $1.2(1.0,1.5)$ & 0.046 & $169(56.0 \%)$ & $1.4(1.0,1.9)$ & 0.026 \\
\hline \multicolumn{7}{|l|}{ EGFR mutation } \\
\hline negative & $195(25.7 \%)$ & 1 & & $86(28.5 \%)$ & 1 & \\
\hline positive & $132(17.4 \%)$ & $0.6(0.4,0.8)$ & $<0.001$ & $54(17.9 \%)$ & $0.7(0.5,1.2)$ & 0.219 \\
\hline unknown & $431(56.9 \%)$ & $1.2(1.0,1.5)$ & 0.093 & $162(53.6 \%)$ & $1.3(0.9,1.8)$ & 0.127 \\
\hline \multicolumn{7}{|l|}{ Sum of metastasis organs } \\
\hline$<2$ & $145(19.1 \%)$ & 1 & & $56(18.5 \%)$ & 1 & \\
\hline$\geq 2$ & $599(79.0 \%)$ & $1.4(1.1,1.7)$ & 0.008 & $241(79.8 \%)$ & $1.4(1.0,2.1)$ & 0.071 \\
\hline unknown & $14(1.8 \%)$ & $1.3(0.7,2.4)$ & 0.348 & $5(1.7 \%)$ & $1.9(0.7,5.3)$ & 0.234 \\
\hline \multicolumn{7}{|c|}{ Treat type of 1st line therapy } \\
\hline Chemo & $378(49.9 \%)$ & 1 & & $194(64.2 \%)$ & 1 & \\
\hline TKI & $118(15.6 \%)$ & $1.0(0.7,1.2)$ & 0.754 & $54(17.9 \%)$ & $1.0(0.7,1.4)$ & 0.916 \\
\hline others & $262(34.6 \%)$ & $1.4(1.1,1.7)$ & 0.001 & $54(17.9 \%)$ & $1.0(0.6,1.5)$ & 0.911 \\
\hline \multicolumn{7}{|l|}{ Sum of treatment line* } \\
\hline$\leq 3$ & $521(88.3 \%)$ & 1 & & $263(87.1 \%)$ & 1 & \\
\hline$>3$ & $69(11.7 \%)$ & $0.5(0.4,0.7)$ & $<0.001$ & $39(12.9 \%)$ & $0.4(0.3,0.6)$ & $<0.001$ \\
\hline \multicolumn{7}{|l|}{$\mathrm{Hb}$} \\
\hline No anemia & $548(72.3 \%)$ & 1 & & $151(50.0 \%)$ & 1 & \\
\hline Anemia & $210(27.7 \%)$ & $1.3(1.1,1.6)$ & 0.008 & $151(50.0 \%)$ & $1.7(1.3,2.3)$ & $<0.001$ \\
\hline
\end{tabular}

ECOG PS: eastern cooperative group performance status, BMI: Body mass index, EGFR: epidermal growth factor receptor, ALK: Anaplastic Lymphoma Kinase, Treatment type of first-line therapy: Chemotherapy, Targeted therapy, others).

$\mathrm{BMI}^{*}$ and Sum of treatment lines* had missing data

${ }^{*} \mathrm{p}$ values $<0.05$ were considered statistically significant. 
Table 3. Effect of Anemia on OS in entire and matched cohorts: results of Cox proportional hazard model.

\begin{tabular}{|c|c|c|c|c|c|c|c|c|}
\hline \multirow[t]{3}{*}{ Variables } & \multicolumn{4}{|c|}{ Before propensity matching } & \multicolumn{4}{|c|}{ After propensity matching } \\
\hline & \multicolumn{2}{|c|}{ Crude model } & \multicolumn{2}{|c|}{ Adjusted model } & \multicolumn{2}{|c|}{ Crude model } & \multicolumn{2}{|c|}{ Adjusted model } \\
\hline & $\mathrm{HR}(95 \% \mathrm{CI})$ & P-value & $\mathrm{HR}(95 \% \mathrm{CI})$ & P-value & $\mathrm{HR}(95 \% \mathrm{CI})$ & P-value & $\mathrm{HR}(95 \% \mathrm{CI})$ & P-value \\
\hline No anemia & 1 & & 1 & & 1 & & 1 & \\
\hline Anemia & $1.3(1.1,1.6)$ & 0.008 & $1.4(1.1,1.7)$ & 0.013 & $1.7(1.3,2.3)$ & $<0.001$ & $1.6(1.1,2.2)$ & 0.003 \\
\hline $\mathrm{Hb}$ (per $1 \mathrm{~g} / \mathrm{dl}$ decrease) & $1.1(1.0,1.1)$ & $<0.001$ & $1.1(1.1,1.2)$ & $<0.001$ & $1.1(1.0,1.2)$ & 0.001 & $1.1(1.0,1.2)$ & 0.018 \\
\hline
\end{tabular}

Crude mode adjusted for: None.

Adjusted model adjusted for: Age; Sex; Smoking history; ECOG PS; BMI; Pathology; Differentiation; ALK fusion; EGFR mutation; Sum of metastasis organs; Treat type of 1st line therapy; Sum of treatment lines

${ }^{*} \mathrm{p}$ values $<0.05$ were considered statistically significant.

Table 4. Effect of Anemia on overall survival with using other studies' cut-off: Cox proportional hazard modeling results.

\begin{tabular}{|c|c|c|c|c|c|c|c|}
\hline \multirow[t]{2}{*}{ First author } & \multirow[t]{2}{*}{ No of cases } & \multirow[t]{2}{*}{ Anemia Cut Off } & \multirow[t]{2}{*}{ Outcome } & \multicolumn{2}{|l|}{ Other Studies } & \multicolumn{2}{|l|}{ Ours } \\
\hline & & & & HR(95\%CI) & p-value & $\mathrm{HR}(95 \% \mathrm{CI})$ & p-value \\
\hline Holgersson et al ${ }^{38}$ & 835 & $<11 \mathrm{~g} / \mathrm{dL}$ & OS & $1.33(1.10,1.61)$ & 0.003 & $1.3(1.0,1.7)$ & 0.059 \\
\hline Pathak et $\mathrm{al}^{9}$ & 752 & $<12 \mathrm{~g} / \mathrm{dL}$ & OS & $1.51(1.03,2.21)$ & 0.030 & $1.4(1.1,1.8)$ & 0.002 \\
\hline Belbaraka et al ${ }^{11}$ & 45 & $\begin{array}{l}\text { male }<13 \mathrm{~g} / \mathrm{dL} \text {, } \\
\text { female }<11.5 \mathrm{~g} / \mathrm{dL}\end{array}$ & OS & $2.78(1.29,5.99)$ & 0.009 & $1.4(1.1,1.9)$ & 0.009 \\
\hline Park et al ${ }^{13}$ & 630 & $\begin{array}{l}\text { male }<13 \mathrm{~g} / \mathrm{dL} \text {, } \\
\text { female }<12 \mathrm{~g} / \mathrm{dL}\end{array}$ & OS & $1.31(1.03,1.68)$ & 0.030 & $1.4(1.1,1.7)$ & 0.004 \\
\hline
\end{tabular}

Our cohort were adjusted for: Age; Sex; Smoking history; ECOG PS; BMI; Pathology; Differentiation; ALK fusion; EGFR mutation; Sum of metastasis organs; Treat type of 1st line therapy; Sum of treatment lines.

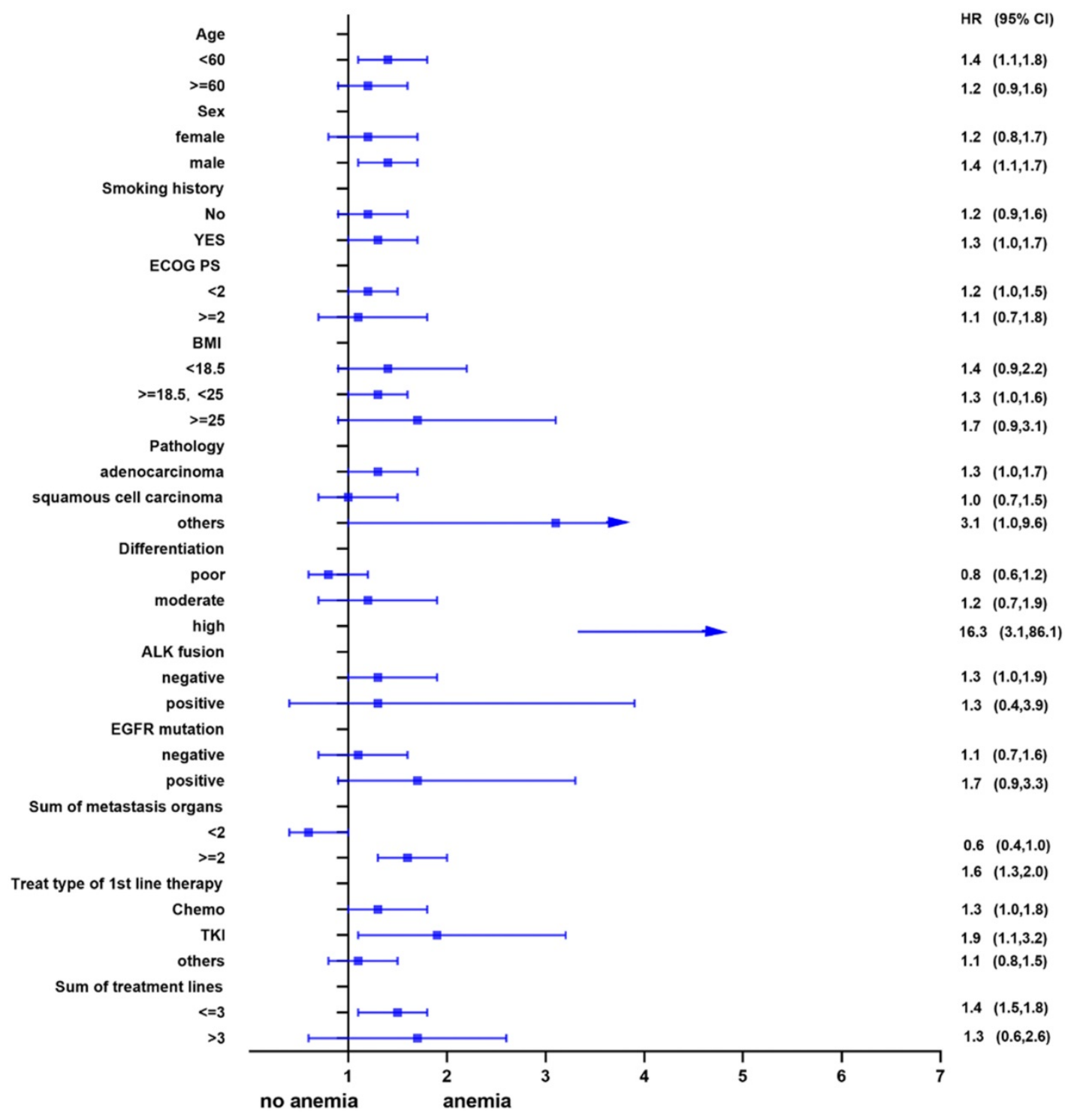

Figure 2. Subgroup analysis before propensity matching. 


\section{Prognostic effect of Anemia on OS with different cut-off values used in other studies}

Previous studies have indicated the association of anemia with shorter OS in patients with lung cancer. However, the definition of anemia varies in different studies. Therefore, as a sensitivity analysis, we used the different cut-off values proposed by those studies to identify further the prognostic effect of anemia on OS in our cohort (Table 4), and found that irrespective of the differences in definition of anemia, the results had a highly consistent $\mathrm{HR}$, indicating that anemia was stably related to an unfavorable prognosis in OS.

\section{Discussion}

Anemia, one of the most common clinical abnormalities, is often associated with the course of lung cancer. It has been reported that the prevalence of anemia in lung cancer patients is approximately 77$80 \%[26,27]$. To determine the incidence of anemia in patients with advanced NSCLC, we studied the clinical data of patients with advanced stage IIIB - IV NSCLC, who had no previous history of anemia, and excluded the factors causing anemia by non-tumor conditions. The results showed that the prevalence of anemia among 758 patients was $27.7 \%$. In a large-scale, prospective, and observational study conducted in Europe, the prevalence of anemia in lung cancer patients was $37.6 \%(753 / 2002)$ [28]. In another multicenter cross-sectional study conducted in China in 2012, the incidence of anemia in lung cancer patients was even higher-50.69\% (988/1949) [6]. The lower percentage of anemia in our study might be attributed to our focus on hemoglobin level in pretreatment patients. Another reason might be that the patients who had a history of anemia were excluded from the study. Besides, some studies had the patients enrolled if the anemia occurred during the treatment, which may explain, in part, the differences in the occurrence rate of anemia.

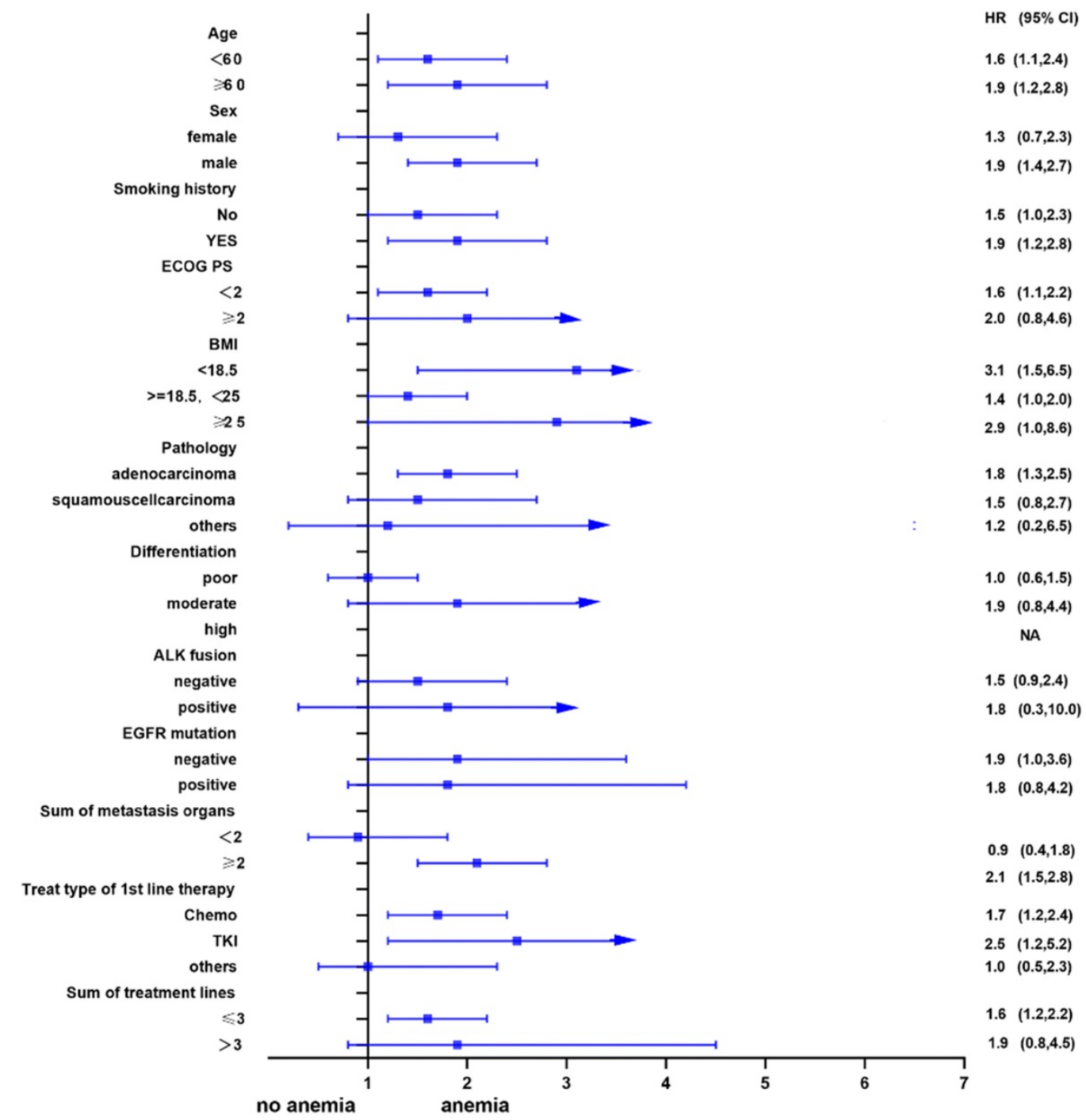

Figure 3. Subgroup analysis after propensity matching. 
$\mathrm{HB}+$ No anemis + Anemis
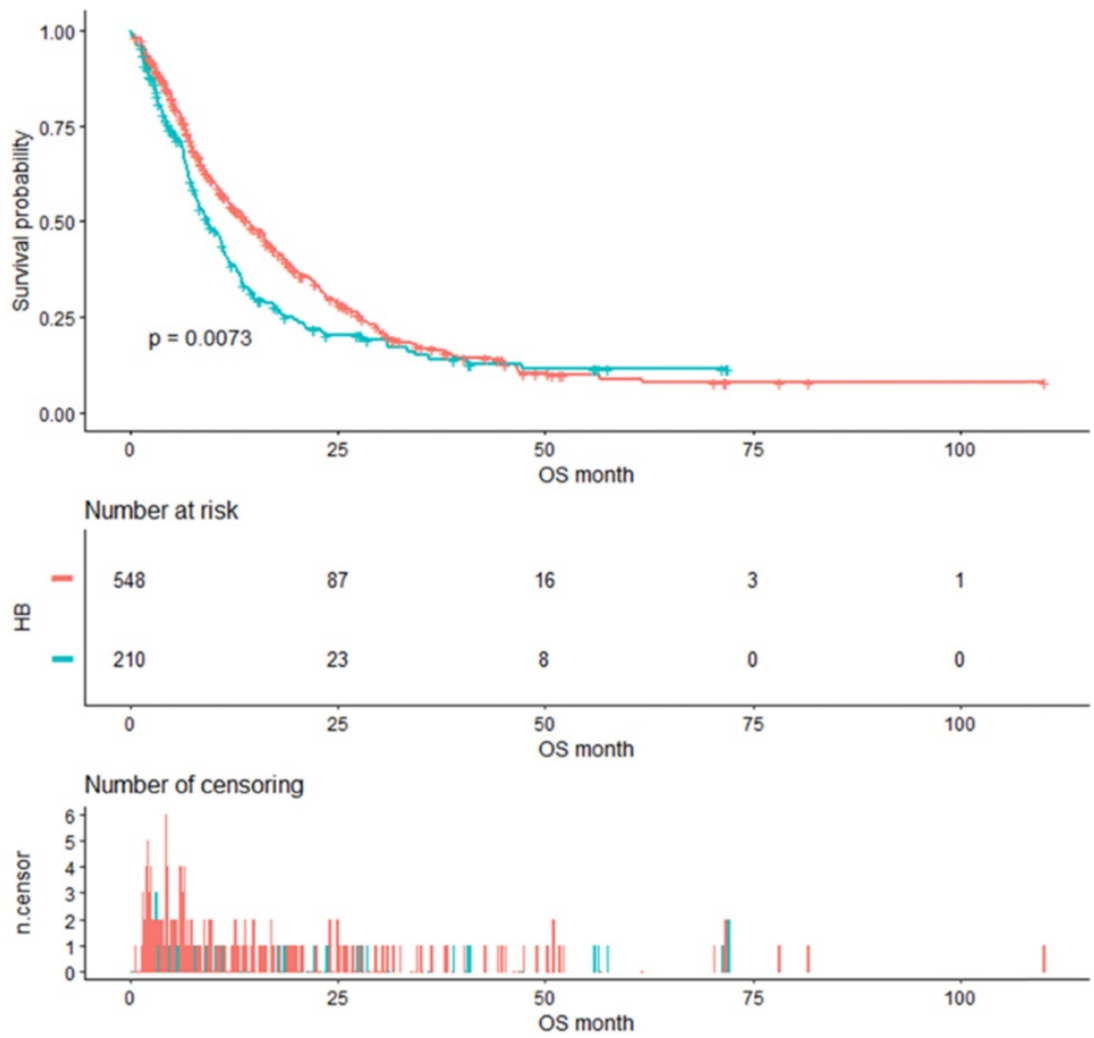

Figure 4. Kaplan-Meier analysis of $\mathrm{Hb}$ level before propensity score matching.

$\mathrm{HB}+$ No anemis $\rightarrow$ Anemis
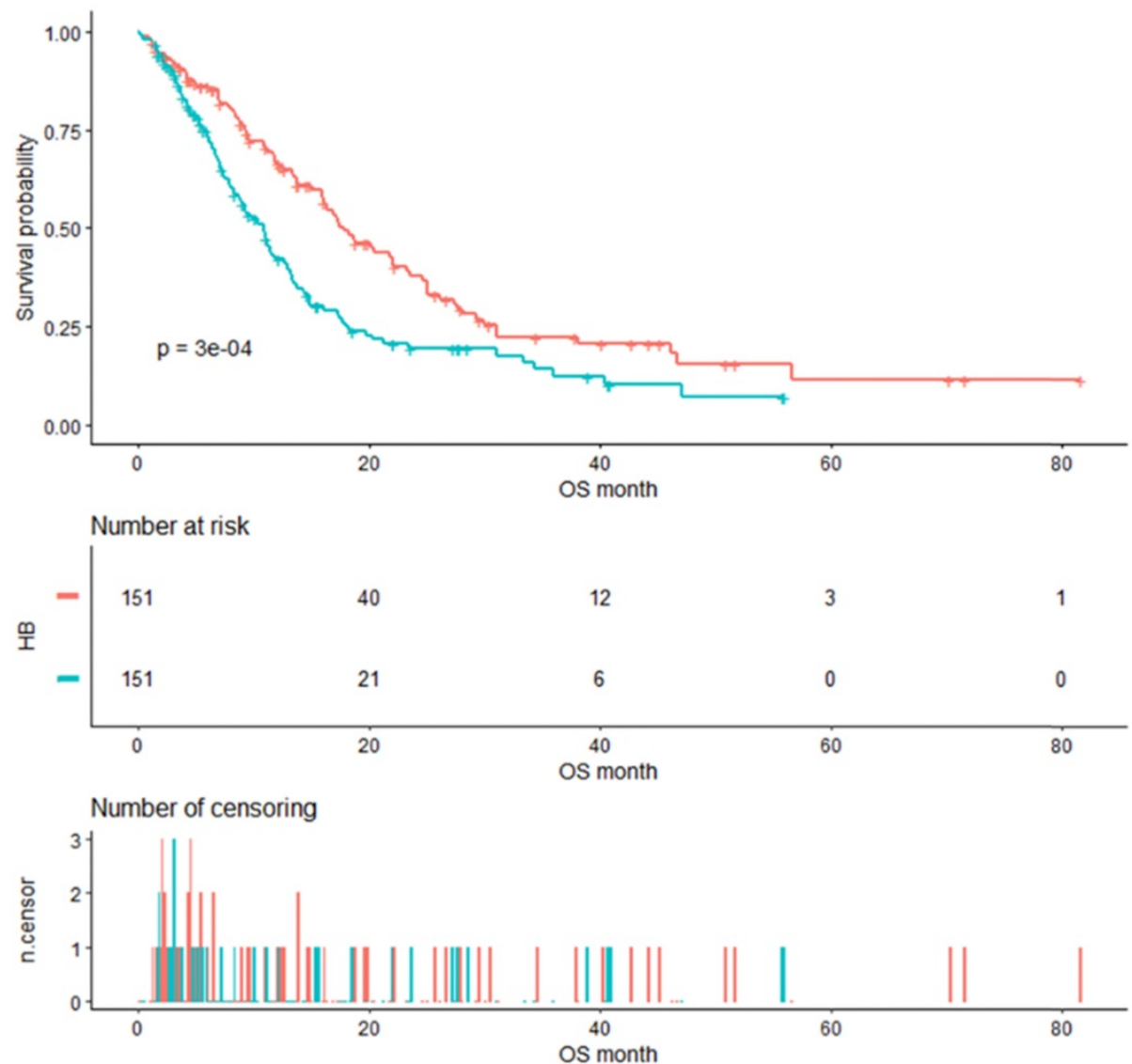

Figure 5. Kaplan-Meier analysis of $\mathrm{Hb}$ level after propensity score matching. 
The reasons for tumor-associated anemia are complex and multifactorial, such as malnutrition caused by long-term anorexia, inhibition of iron metabolism, erythropoiesis by tumor-related inflammatory factors, blood loss, and bone marrow metastasis $[29,30]$. Some studies suggest that the main reason for anemia is that the level of iron regulatory hormone (hepcidin) is upregulated in patients with multiple myeloma and Hodgkin's lymphoma. This can promote the transcription and synthesis of iron transporters, and eventually affect intestinal iron absorption, interfere with iron release from the monocyte-macrophage system, and disturb iron transport [29, 30]. In addition, many inflammatory factors, such as interleukin-6 (IL-6), tumor necrosis factor - $\alpha$, IL-1, interferon- $\gamma$, and erythropoietin (EPO) are involved in the pathogenesis of tumor-associated anemia [31, 32].

As a paraneoplastic phenomenon of tumors, anemia results in mental depression and fatigue and reduces the immunity of patients, both of which seriously affect the quality of life of patients. Meanwhile, besides contributing to tissue oxygenation disorders, anemia has been shown to aggravate tumor-associated hypoxia, stimulate tumor angiogenesis, and produce proteomic changes affecting tumor dissemination. It also affects the efficacy of radiotherapy and chemotherapy, worsening the prognosis of patients [33-35]. A Japanese study revealed that the OS of patients with lung cancer and anemia was significantly shorter than patients without anemia [36]. Hsu [8] et al. also identified anemia as a poor prognostic factor after conducting a study in advanced lung cancer patients aged 45 years or younger. It is worth noting that anemia was also associated with poor prognosis in NSCLC patients who received targeted therapies [13]. Our study demonstrated that irrespective of the use of PSM, anemia was an independent risk factor for prognosis in patients with advanced NSCLC, as per the results of the multivariate Cox proportional hazard model. All these results indicate that anemia could enhance the aggressive behavior of the tumor and worsen physical condition of the patients.

Meanwhile, it was also observed that lower hemoglobin level was associated with worse disease prognosis in the patients. We observed that for every $1 \mathrm{~g} / \mathrm{dL}$ decrease in $\mathrm{Hb}$, the risk of death increased by 10\%. Nevertheless, Crvenkova [37] failed to demonstrate the prognostic effect of anemia in IIIA and IIIB NSCLC patients treated with chemoradiotherapy $(\mathrm{P}=0.06)$. Gong [16] et al. also did not find any significant correlation between anemia and survival in NSCLC patients receiving first-line chemotherapy. The divergent results of these studies may be attributed to differences in study design, scale, race, and clinicopathological features. Most importantly, the imbalance between the two groups under comparison could also have a crucial influence on the results.

To the best of our knowledge, this is the first study to employ a propensity score matching approach to analyze the relationship between pretreatment anemia and OS in patients with NSCLC. Propensity score matching was extensively used in observational studies to control confounding and minimize the differences between the two groups. To date, a growing number of studies have used propensity score matching to balance covariates across treatment groups and achieved better results. Our cohort found that using PSM to match two groups resulted in the derivation of similar conclusions.

Of note, the definition of anemia differs in different studies, which may be another critical factor influencing the final results. We used the National Cancer Institute criteria and the ninth edition of Diagnostics in China definition, which represents the Chinese population. Therefore, the corresponding findings from our observations could be helpful for decision-making in clinical practice. To eliminate the effect of different definitions of anemia on the prognosis OS, we used different cut-off values proposed by various studies as a sensitivity analysis and re-evaluated the results in our cohort. The findings showed that irrespective of the differences in definition, the results were highly consistent in HR.

Although our study adjusted for covariates against previous studies, the study still has the following limitations: (1) this was a retrospective study conducted in a single institute and did not include an independent and prospective cohort to validate the prognostic value of anemia; (2) although adjustments for potential confounders had already been carried out, there was a possibility of presence of residual or unknown confounders; (3) since the study focused on pretreatment anemia in advanced NSCLC patients, the conclusion is not suitable for patients who are in the early stage of NSCLC or present with anemia during disease after treatment; (4) data on subjects taking anti-anemic drugs during disease progression was not collected; therefore, the role of anti-anemic drugs in the improvement of clinical outcomes of the disease remains unknown and needs to be investigated further.

\section{Conclusion}

In summary, anemia at baseline was an independent risk factor for patients with advanced NSCLC. This simple and convenient serological 
method of detection enabled rapid prediction of patient prognosis. In the future, extensive analyses involving a large-scale prospective cohort study are necessary to confirm our findings.

\section{Abbreviations}

NSCLC: Non-small cell lung cancer; PSM: Propensity score matching; HR: Hazards ratio; CI: Confidence interval; OS: Overall survival; AJCC: American Joint Committee on Cancer; ECOG PS: Eastern cooperative oncology group performance status; BMI: Body mass index; ALK: Anaplastic lymphoma kinase; EGFR: Epidermal growth factor receptor; HB: Hemoglobin; WHO: World Health Organization; FISH: Fluorescence in situ hybridizations; IHC: Immunohistochemistry; RT-PCR: Reverse transcription-polymerase chain reaction; ARMS: Amplification refractory mutation system; ddPCR: Droplet digital polymerase chain reaction; NGS: Next-generation sequencing; EPO: Erythropoietin.

\section{Acknowledgments}

This work was supported by the "139 Talent Planning" granted by Guangxi Health Commission, Guangxi Zhuang Autonomous Zone, China (grant number: 201903030).

\section{Competing Interests}

The authors have declared that no competing interest exists.

\section{References}

1. Feng RM, Zong YN, Cao SM, Xu RH. Current cancer situation in China: good or bad news from the 2018 Global Cancer Statistics? Cancer Commun (Lond). 2019; 39: 22.

2. Bray F, Ferlay J, Soerjomataram I, Siegel RL, Torre LA, Jemal A. Global cancer statistics 2018: GLOBOCAN estimates of incidence and mortality worldwide for 36 cancers in 185 countries. CA Cancer J Clin. 2018; 68: 394-424.

3. Liu Y, Bai YP, Zhou ZF, Jiang CR, Xu Z, Fan XX. Preoperative anemia as a prognostic factor in patients with lung cancer: a systematic review and meta-analysis of epidemiological studies. J Cancer. 2019; 10: 2047-56.

4. Siegel RL, Miller KD, Jemal A. Cancer statistics, 2019. CA: A Cancer Journal for Clinicians. 2019; 69: 7-34.

5. Gaspar BL, Sharma P, Das R. Anemia in malignancies: pathogenetic and diagnostic considerations. Hematology. 2015; 20: 18-25.

6. Zhengbo Song SLJFJX, Yunpeng Liu, Wei Liu, Weiming Zhang, LI Zhang, Cheng Huang, Suxia Luo, Yiping Zhang, Jun Zhu, Jiejun Wang. Prevalence and Treatment of Cancer-related Aneima:A Nationwide Survey in China. China Cancer. 2019; 28: 718-22.

7. Qu X, Zhang T, Ma H, Sui P, Du J. Lower mean corpuscular hemoglobin concentration is associated with unfavorable prognosis of resected lung cancer. Future Oncol. 2014; 10: 2149-59.

8. Hsu CL, Chen KY, Shih JY, Ho CC, Yang CH, Yu CJ, et al. Advanced non-small cell lung cancer in patients aged 45 years or younger: outcomes and prognostic factors. BMC Cancer. 2012; 12: 241.

9. Pathak RS, Pantarotto JR, Cook G, Holmes O, Cross P, MacRae RM. Anemia is a poor prognostic factor for stage I non-small cell lung cancer (NSCLC) patients treated with Stereotactic Body Radiation Therapy (SBRT). Clin Transl Radiat Oncol. 2019; 16: 28-33.

10. Kishida Y, Hirose T, Shirai T, Sugiyama T, Kusumoto S, Yamaoka T, et al. Myelosuppression induced by concurrent chemoradiotherapy as a prognostic factor for patients with locally advanced non-small cell lung cancer. Oncol Lett. 2011; 2: 949-55.

11. Belbaraka R, Tredan O, Ray-Coquard I, Chvetzoff G, Bajard A, Perol D, et al. Factors of interrupting chemotherapy in patients with Advanced Non-Small-Cell Lung Cancer. BMC Res Notes. 2010; 3: 164.

12. Oguz A. The Effect of Haematological Parameters on Overall Survival in Advanced Stage Non Small Cell Lung Cancer. International Journal of Hematology and Oncology. 2014; 24: 82-8.

13. Park S, Park S, Lee SH, Suh B, Keam B, Kim TM, et al. Nutritional status in the era of target therapy: poor nutrition is a prognostic factor in non-small cell lung cancer with activating epidermal growth factor receptor mutations. Korean J Intern Med. 2016; 31: 1140-9.

14. Lee S, Eo W, Jeon H, Park S, Chae J. Prognostic Significance of Host-related Biomarkers for Survival in Patients with Advanced Non-Small Cell Lung Cancer. J Cancer. 2017; 8: 2974-83.

15. Wu XY, Huang XE. Screening for patients with non-small cell lung cancer who could survive long term chemotherapy. Asian Pac J Cancer Prev. 2015; 16: 647-52.

16. Gong J, Xu L, Li Z, Hu X, Liu J, Teng Y, et al. A Clinical Prognostic Score to Predict Survival of Advanced or Metastatic Non-Small Cell Lung Cancer (NSCLC) Patients Receiving First-Line Chemotherapy: A Retrospective Analysis. Med Sci Monit. 2018; 24: 8264-71.

17. Holgersson G, Bergqvist M, Nilsson J, Thureson M, Harmenberg J, Bergstrom S. The Prognostic Value of Pre-Treatment Leukocytosis in Patients with Previously Treated, Stage IIIB/IV Non-Small Cell Lung Cancer Treated with the IGF-1R Pathway Modulator AXL1717 or Docetaxel; a Retrospective Analysis of a Phase II Trial. Asian Pac J Cancer Prev. 2017; 18: 1555-60.

18. Imai H, Kaira K, Mori K, Ono A, Akamatsu H, Matsumoto S, et al. Prognostic significance of diabetes mellitus in locally advanced non-small cell lung cancer. BMC Cancer. 2015; 15: 989.

19. Jun M, Jiejun W, Li Z, Shukui Q. Clinical guidelines on tumor associated anemia (Version 2015-2016). Chinese Journal of Practical Internal Medicine. 2016; 36: 1-21.

20. Jiejun W, Li Z, Yuankai S, Jun Z, Jianmin W, Shun L, et al. Chinese Specialist Consensus on Erythropoietin in the Treatment of Cancer-related Anemia(Version 2010-2011). Chinese Clinical Oncology. 2010; 15: 925-36.

21. Wan X, Lu X. Diagnostics. BeiJing: People's Medical Publishing House; 2015.

22. Taghizadeh N, Boezen HM, Schouten JP, Schröder CP, Elisabeth de Vries EG, Vonk JM. BMI and lifetime changes in BMI and cancer mortality risk. PLoS One. 2015; 10: e0125261.

23. Shepshelovich D, Xu W, Lu L, Fares A, Yang P, Christiani D, et al. Body Mass Index (BMI), BMI Change, and Overall Survival in Patients With SCLC and NSCLC: A Pooled Analysis of the International Lung Cancer Consortium. J Thorac Oncol. 2019; 14: 1594-607.

24. Ziogas DC, Tsiara A, Tsironis G, Lykka M, Liontos M, Bamias A, et al. Treating ALK-positive non-small cell lung cancer. Ann Transl Med. 2018; 6: 141.

25. Loong HH, Kwan SS, Mok TS, Lau YM. Therapeutic Strategies in EGFR Mutant Non-Small Cell Lung Cancer. Curr Treat Options Oncol. 2018; 19: 58.

26. Ludwig H, Van Belle $S$, Barrett-Lee P, Birgegård G, Bokemeyer C, Gascón P, et al. The European Cancer Anaemia Survey (ECAS): a large, multinational, prospective survey defining the prevalence, incidence, and treatment of anaemia in cancer patients. Eur J Cancer. 2004; 40: 2293-306.

27. Tiotiu A, Clément-Duchêne C, Martinet Y. [Management of chemotherapy-induced anemia in lung cancer]. Rev Mal Respir. 2015; 32: 809-21.

28. Kosmidis P, Krzakowski M. Anemia profiles in patients with lung cancer: what have we learned from the European Cancer Anaemia Survey (ECAS)? Lung Cancer. 2005; 50: 401-12.

29. Ganz T. Hepcidin and iron regulation, 10 years later. Blood. 2011; 117: 4425-33.

30. Kroot JJ, Tjalsma H, Fleming RE, Swinkels DW. Hepcidin in human iron disorders: diagnostic implications. Clin Chem. 2011; 57: 1650-69.

31. Grigorakaki C, Morceau F, Chateauvieux S, Dicato M, Diederich M. Tumor necrosis factor a-mediated inhibition of erythropoiesis involves GATA-1/GATA-2 balance impairment and PU.1 over-expression. Biochem Pharmacol. 2011; 82: 156-66.

32. Barni S, Cabiddu M, Guarneri P, Lonati V, Petrelli F. The risk for anemia with targeted therapies for solid tumors. Oncologist. 2012; 17: 715-24.

33. Abdel-Razeq H, Abbasi S, Saadi I, Jaber R, Abdelelah H. Intravenous iron monotherapy for the treatment of non-iron-deficiency anemia in cancer patients undergoing chemotherapy: a pilot study. Drug Des Devel Ther. 2013; 7: 939-44. 
34. Dubsky P, Sevelda P, Jakesz R, Hausmaninger H, Samonigg H, Seifert M, et al. Anemia is a significant prognostic factor in local relapse-free survival of premenopausal primary breast cancer patients receiving adjuvant cyclophosphamide/methotrexate/5-fluorouracil chemotherapy. Clin Cancer Res. 2008; 14: 2082-7.

35. Harada H. How can we overcome tumor hypoxia in radiation therapy? J Radiat Res. 2011; 52: 545-56.

36. Tomita M, Shimizu T, Hara M, Ayabe T, Onitsuka T. Preoperative leukocytosis, anemia and thrombocytosis are associated with poor survival in non-small cell lung cancer. Anticancer Res. 2009; 29: 2687-90.

37. Crvenkova S. Prognostic Factors and Survival in Non-Small Cell Lung Cancer Patients Treated with Chemoradiotherapy. Open Access Maced J Med Sci. 2015; 3: 75-9.

38. Holgersson G, Sandelin M, Hoye E, Bergström S, Henriksson R, Ekman $S$, et al. Swedish lung cancer radiation study group: the prognostic value of anaemia, thrombocytosis and leukocytosis at time of diagnosis in patients with non-small cell lung cancer. Medical Oncology. 2012; 29: 3176-82. 